REFLEXIŌN 


\title{
EL MOVIMENT: \\ LECTURA D'UN FRAGMENT \\ DEL FRIS DEL CASTELL \\ D'URGELLET
}

\author{
R. Arola
}

La reflexió sobre les obres d'art medievals exhaureix; en molts sentits és una reflexió quasi bé impossible, s'escapa de les velles i sàvies ments dels europeus. Cerquem necessitats i desitjos en les «nostres» obres d'art simbòliques; hem après a imaginar-les i a somniar-les, però de molt no les posseìm. Les festegem amb els més hàbils arguments, però elles no contesten, sols ens miren, tant abans com després de parlar; reflexionem. Exhaureix. Què pensen aquells ulls que ens miren frontalment?, i per què miren tant? Sabem que no podem renunciar a les obres d'art medievals, que no podem sinó continuar insistint, buscant el contingut - com a pregunta estricta - de llurs formes. Un contingut que està, bàsicament, en el canvi, el moviment.

A finals del segle XII l'art romànic del sud proposava les formes convenients d'una propaganda visual; en aquella època qualsevol intent de canvi havia de construir-se sobre l'obra d'art; fins llavors era el punt neuràlgic del coneixement. Però estava estrictament lligada a l'Església; era com el coneixement, sagrada. Les obres d'art que diem romàniques eren per a ser la Glòria de Déu i el terror del mal; en l'època del canvi del segle XII al segle XIII hi ha una sèrie d'obres que, tot i tenint l'estructura interna de l'art sagrat anterior, no són sagrades. L'exemple que analitzarem, un 
fragment del fris del Castell d'Urgellet ${ }^{1}$ és una d'aquestes obres solitàries a cavall entre - en termes d'història de l'art-el Romànic i el Gòtic; com veurem, el sisrema d'estructuració interna d'aquesta pintura al fresc no es diferencia gens de l'art romànic, però sorgeix fora del marc eclesiàstic i representa guerres i batalles, castells, bèsties, etc. El desencaixament entre la intencionalitat i el sistema operatiu exigirà un canvi profund de l'obra d'art; un canvi marcat per la desacralització formal i de continguts $i$, en definitiva, un canvi del sistema de pensament. En el sistema operatiu i cognoscitiu del romànic no hi ha fissures pels implícits, s'estructura en l'explicitat, no tế dubtes, no és laberíntic, i no serveix, per tant, a la intenció de canvi que neix dintre de la cort ${ }^{2}$.

\section{PRIMER}

L'u és desencadenat, la Unitat reposa. L'obra d'art romànica no comença mai per l'u (com en molts sentits farà el Gòtic i les maneres que vénen després); les obres d'art romàniques comencen en la Unitat, com també, lògicament, les obres d'art post-tomàniques, com el fris del Castell d'Urgellet.

La Unitat es diferencia de l'u en tant que no indica l'inici d'un sistema operatiu, no és l'axioma de partida. La Unitat és el sincronisme perfecte de les parts, llur estat d'equilibri, d'assentament, de repòs ${ }^{3}$. Aquest estat sols es pot donar en allò que és-complert, en el conjunt que crea un organisme perfecte i on les parts circulen en la interrelació.

La Unitat simbòlicament pertany a dalt, al cel; és pròpia de Déu, mostra la seva glôria i esplendor, i en aquest sentit podem dir que la Unitat és perfecta, ja que és bàsicament exemplaritat celestial; fora d'ací no hi ha art sacre (pel que fa al contingut).

Al sistema mental de l'home del segle XX li costa en gran manera entendre el principi com Unitat, això és, que - $i$ a nivell d'obra d'art-el primer contacte ofereixi internament tota la res-

1 El fris es troba en el Museu d'Art de Catalunya, de Barcelona; ñ catà. leg 68712 .

2 Vegeu per a aquesta reflexió, I. RIERA i R. AROLA, slmatge i representació del matrimoni català del segle XIıs, Medievalia 4, 1982.

3 La sèrie de nombres unitaris és $1,4,7,10$, etc. Vegeu la nota 16 d'aquest article. 
ta, que el punt primer dintre de l'obra tingui «escrit el contigut final. El nostre sistema mental no pensa simbòlicament, sinó fragmentàriament, discursivament $\mathrm{i}$ per tant no pot reconềixer la Unitat més que en la suma de les diferents parts. En canvi, un pensament que sorgeix de l'exemplaritat celestial mai és linial, desglossiu, sinó fonamentalment sintètic, sincrònic, mai la suma de les parts mostrarà la síntesi. Una obra d'art sagrada - simbòlica - tê un sol punt de partida, aquest és: la presència de Déu en la terra (és hierofònica), qualsevol que sigui aquesta presència, si és, és complerta, Unitària.

Aquest sentit de la Unitat ens importa tant pràcticament com teòricament. La qüestió és la següent: el fris del Castell d'Urgellet és un conjunt unitari, compacte, complert, quan el volem analitzar - traduir-lo mínimament a un sistema de comprensió del segle $\mathrm{XX}$ - topem amb una gran dificultat, com desenvolupem el procés analític?, com entrem en el sincronisme plàstic utilitzant el discurs? Això és sumament complex, exhaureix la ment; ara bé, és imprescindible intentar-ho per poder continuar, però que vagi per endavant el nucli de dificultat: la partició arbitrària per construir un discurs, que a la fi serà igual, com a molt, que la mateixa imatge de la qual hem partit. Inevitable, perquè els nostres ulls no veuen $\mathrm{i}$ les nostres orelles no escolten.

M'imagino una església romànica, ho prefereixo més que discursejar-la; m'imagino el soroll dels cants, els colors de les parets i les llums de les espelmes, les olors d'encens, molta gent al costat; m'imagino el transcórrer del rite. Somnio la sala del Castell d'Urgellet plena de senyors menjant $i$ bevent com a veritables animals; riuen, canten, mengen per destruir el menjar.

\section{LECTURA}

El fris del Castèll d'Urgellet té una forma rectangular de $8,80 \mathrm{~m}$ per $3,74 \mathrm{~m}$ i una alçada de poc més d'un metre. El seu estat de conservació és irregular, i mentre que hi ha zones força ben conservades, altres són quasi bé inidentificables; aquestes importants llacunes impossibiliten d'entrada l'anàlisi completa del fris. Localitzem un fragment que no es pot deslligar del conjunt, i encara que sigui des d'una perspectiva introductòria, hem de situar l'escena en el context propi i general, pensar-la en el temps que és tot 
el fris. En el dibuix primer (d-1) podem situar l'escena que ens interessa (escena 1-a).
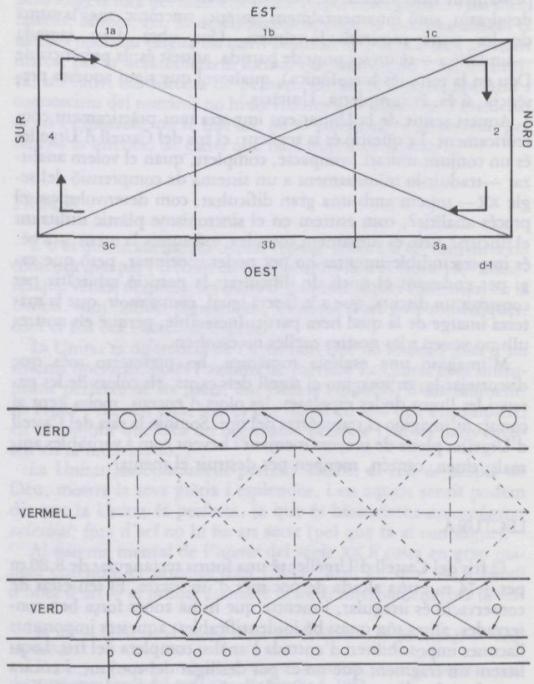
Tot el fris està dividit en tres zones verticals, de baix a dalt són: una franja ornamental, una franja central - on es situen els personatges - i una tercera franja ornamental. Pels trossos del fris en mal estat de conservació podem veure clarament els colors de fons primers de cada franja; així podem veure que les dues franges ornamentals estan sobre el color vermell, mentre que en la central el color del fons és el verd. Vermell i verd, colors complementaris. En les franges ornamentals el color vermell, color bàsic, el color ocult en la natura que mostra allò intern i vital; sota els personatges el color verd - unió de dos colors bàsics: blau i groc- que és el color manifestat de la natura. Aquesta divisió cromàtica ens adverteix de la reciprocitat entre la figuració i l'ornamentació. No podem oblidar l'ornamentació, és absolutament fonamental en l'art que anomenem romànic, al nivell que estem sols apuntem el seu funcionament (vegeu el dibuix segon, d-2).

En l'escena 1-a podem analitzar la trama estructural del fris en la franja central, la conjunció d'aquesta escena és la mateixa de tot el fris. Com es pot veure en la fotografia hi ha en aquesta escena d'esquerra a dreta: una lluita d'un home i un lleó (?), després un edifici amb dues arcades i dintre de cada una un personatge, després un arbre, $i$, finalment, una altra lluita entre un guerrer i un lleó. Aquesta lluita té importància per a nosaltres, ja que podem localitzar un punt de partida que no té equivocació: l'espasa'. L'espasa crea un angle de 45 graus; si projectem la línia de l'espasa tenim la línia B-C' (vegeu el dibuix tercer, d-3); com a conseqüència tenim també la línia $B^{\prime}$-C, i d'ací el quadrat B-B'-C-C'. La línia B-B' limita l'edifici pel costat dret, mentre que la línia C.C' dóna exactament la vertical del guerrer; en l'encreuament de les diagonals del quadrat, al centre, hi ha l'arbre, allí on es separen el tronc $i$ les branques, el punt 2 del dibuix.

Un cop determinat aquest quadrat és simple traslladar-lo per l'escena, a l'esquerra es configura, doncs, el quadrat B-B'-A-A', que ens dóna exactament els límits de l'edifici; en el punt central d'aquest quadrat, el punt 1 resultat de l'encreuament de les diagonals se situa el pilar que separa les arcades; el punt està situat on es separen la columna pròpiament del capitell. Més a l'esquerra hi

4 Ens recolzem bàsicament en l'article de V. CirLot. „Ornamento y abstracción: ritmos lineales en la pintura de Sant Martí Sescortsw, Estudios pro-Arte 9 , 1977 , pp. $75-77$. 
ha la primera lluita, però en molt mal estat de conservació encara que es pot continuar la trama de quadrats.

-Aquesta trama és el suport de les escenes del fris; no ens pot estranyar ja que tot l'art medieval està construitt geomètricament sobre la trama que determina el quadrat i les seves diagonals - això és: en base a l' $\sqrt{2}$ - que conté el principi configurador de la divisió, de la separació com a sentit de la dinàmica interna de l'obra d'art's. Ara bé, la construcció sobre l' $\sqrt{2}$ no explica suficientment la trama interna del fris. L' $\sqrt{2}$ implica també l' $\sqrt{3}$; el procés gràfic que ho explicaria és el següent: prenent com a centres els punts 1 i 2 tracem un cercle intern als quadrats que hem vist; després tracem els cercles que amb el mateix radi es creuen amb aquests, amb els centres a, b i c; al final ens queda un moviment de distintes mandorles, que, i a diferència dels quadrats, estan determinades exactament pel tamany de la franja central. Aquesta distància concebuda des de la mandorla és l' $\sqrt{3}$. Si l' $\sqrt{2}$ és el principi de separació, l' $\sqrt{3}$ és el principi d'unió, de centre, que com la mandorla uneix dues parts; a partir d'ella apareix una trama absolutament importat i complementària de la trama dels quadrats. aquesta és la trama de triangles equilàters, d'angles de 30 graus $^{\prime}$.

Sobre l' $\sqrt{2}$ i l' $\sqrt{3}$ es van construint les escenes del fris, es pot veure en el dibuix. Hi ha molts possibles matisos, però allargarien massa aqui. Tornem a les figures. Podem observar primer la configuració d'una escena estàtica: els dos personatges dintre de l'edifici, cadascun està inscrit perfectament dintre d'una mandorla, que es reforça amb el sentit simbòlic de l'are de ferradura.

Al costat d'aquesta escena hi ha la lluita entre el guerrer i el lleó; podem veure com es segueix també la trama estrictament. Seguint una diagonal hi ha l'espasa, seguint la contrària hi ha el lleó, ambdós s'ajuntaran en el següent moviment; entre l'espasa i el lleó es situa la verticalitat del guerrer, formant una creu, on el centre és la panxa justament: no ens pot estranyar estant, com estem, molt pròxims a l'art romànic ?

El primer nivell de traducció ens revela ja moltes coses; l'estructuració dels personatges i de les escenes explicaria per ella mateixa quasi bé tots els continguts que li són escaients. Potser, tanma-

5 Cfr. R. Lawlor, Sacret Geometry, London 1982, pp. 23-31.

6 Ibidem, pp. 32-35.

7 Cfr. A. Scobeltzine, L'art feudal et la sociêté, Paris 1976. 


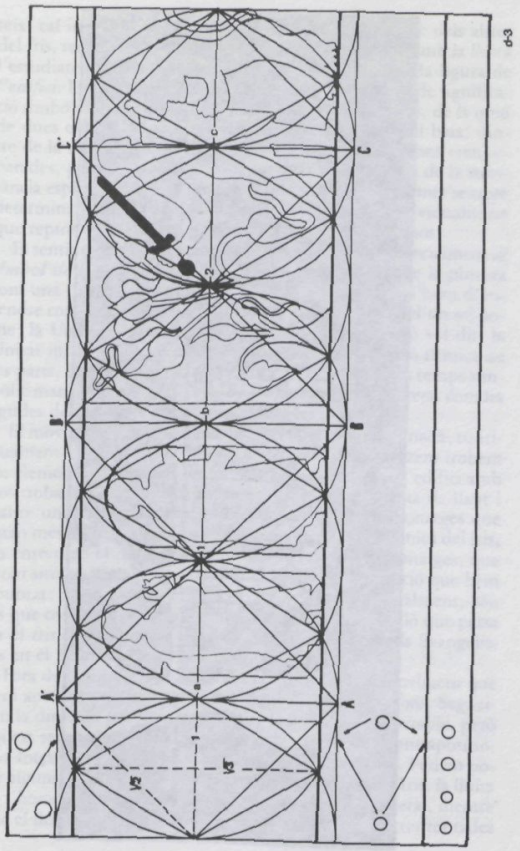




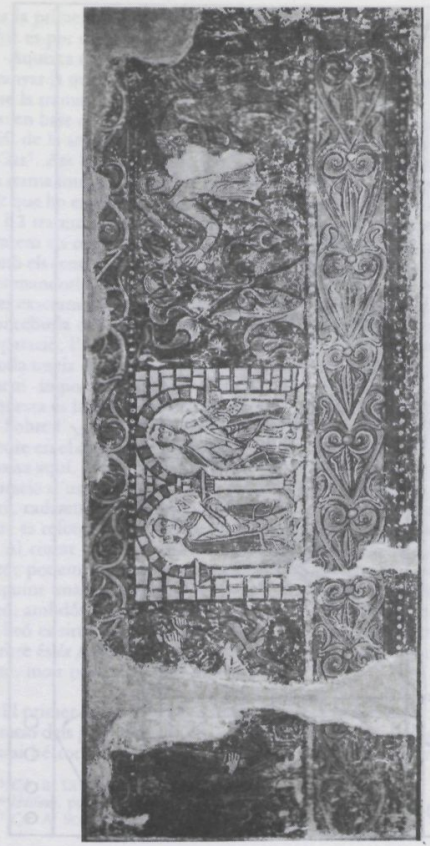


teix, cal insistir. Els temes són ja reveladors, al marge dels altres del fris, recordem-los: la figura de l'bome. La relació amb la lluita l'estudiarem a la propera part, la figura de l'arbre i la figura de l'edifici. Home, arbre i edifici tenen un mateix nivell de significació simbòlica que es pot resumir pel seu caràcter de tres, de la unió de dues esferes de realitat: es situen entre el dalt i el baix, dintre de la mandorla; com uneixen dues esferes que abans eren separades, participen tant de la substància terrenal com de la substãncia espiritual; la seva imatge és una imatge que permet sempre determinar-se com un microcosmos: organismes individualitzats que reprodueixen l'organisme còsmic - el macrocosmos.

El sentit del fris com a sentit d'Unitat està lligat especialment al simbol de l'bome. No podem entendre el conjunt de la pintura com una suma de diferents panoràmiques, sinó que l'hem d'entendre com a diferents parts que són qualitats o estats d'un sol home: la Unitat és tant estructural com de sentit. Aixõ vol dir: la Unitat internament té un moviment, una coordinació rítmica de les parts, en definitiva, el fris té una temporalitat. Un temps sim. bòlic marcat per una direcció, de l'esquerra cap a la dreta, com les agulles del rellotge, que va encadenat les parts.

El moviment és cíclic, no té un inici i una fi determinada, continuament es troben. Ara bé, en l'exemple que analitzem trobem un element introductori, de presentació: l'escena de l'edifici amb dos trobadors dintre, dos músics, l'un toca una mena de llaüt i l'altre una mena de castanyoles (?); són els dos personatges que estan més externament situats del moviment i la dinàmica del fris, no entren en el moviment com tota la resta de personatges, que estan situats lateralment marcant el sentit de la direcció que hem apuntat: aquests dos personatges estan situats frontalment, són els que conten la història, com si fossin els autors d'allò que passa en el fris, introdueixen i situen la història - com els Evangelistes en el Beatus o en un portal romànic.

Fora de l'edifici els personatges van dibuixant el moviment que hem apuntat i no tenen més marc que els colors del fons. Segueixen la direcció; podríem pensar que la direcció és inevitable, però aquest sentit de la direcció té en cada escena una contraposició, una força que actua antagònicament al sentit general. Podem posar alguns exemples dels temes que hi ha a la resta del fris: la lluita de l'home amb el lleó - l'home segueix el sentit general, mentre que el lleó es contraposa; després hi ha dues barques confrontades 
- la cristiana segueix el moviment general mentre que la musulmana es contraposa-, igual passa amb les lluites dels castells; els cavallers caminen sempre en el sentit general fins que entren en la batalla, això és: la contraposició. Només els dos trobadors estan fora de la dinàmica del moviment, del sentit i el contra/sentit, tancars dins d'un edifici, en la cort.

Des d'una perspectiva general el simbolisme que ordena el fris és aquesta direcció que es va trobant amb diferents motors i diferents obstacles que s'han de superar per tal de poder continuar; cada escena és un enfrontament, un punt tensional, d'on es pot entendre la successió d'escenes com si es tractés de la temporalitat musical, cada escena és una fricció i, per tant, produeix un so. $\mathrm{Hi}$ ha, doncs, resistències al seritit de la direcció general i per això hi ha soroll; el conjunt del fris és una alternància del so amb el silenci.

El sentit de la direcció general és el sentit universal - en el sentit etimològic grec d'allò que té un sol «vers»- constituît per diferents parts (o tèmpores); dintre de cadascuna hi ha les friccions, el so. Aquest temps-universal és quelcom que ens interessa lligar amb el que dèiem més amunt: és el personatge.

Una reflexió paral-lela és la que fa M. Merleau-Ponty sobre el temps des d'un punt de vista fenomenològic; diu: ${ }^{N}$ No diem que el temps és per a algú, això equivaldria a exhibir-lo i immobilitzar-lo de nou. Diem que el temps és algú (nosaltres ens referim al personatge), o sigui, que les dimensions temporals, en quant es recobreixen perpètuament, es confirmen unes a altres, no fan res més que explicitar allò que en cadascuna estava implicat, expressant totes una explosió o un únic impuls que és la mateixa subjectivitat ${ }^{8}$.

\section{SEPARACIÓ. LA LLUITA DEL GUERRER I EL LLEÓ}

La lluita del guerrer amb el lleó no pot ser considerada fora de la significació de moviment que té tot el fris; ens aturem en ella per a poder desenvolupar millor el que és el moviment, la temporalització. El motiu, el que diem la lluita, proposa un reconezxement de la presència concreta dels ritmes linials i cromàtics que es-

8 Fenomenología de la percepción, Barcelona 1975, p. 430. 
tructuren la realitat objectual. En el reconeixement traslladem la presència a un contingut; aquest és el sentit del motiu, de les icones; un guerrer del segle XII, a la mà dreta té l'espasa, a l'esquerra un escut, el lleó dret sobre les potes de darrera s'avança sobre l'escut del guerrer, l'espasa del guerrer està presta a replicar l'atac del lleó.

El motiu està dintre del sentit general del moviment. El sentit i el contra/sentit, el transcórrer i les resistències; ambdós es lliguen rítmicament donant peu al moviment. Situats en el alloc» del canvi podrem veure els fonaments del moviment que, principalment, vindran donats pel que direm: trànsit entre dues esferes de realitat ${ }^{\prime \prime}$. Dues esferes que s'han de separar, discernir, per tal de poder saber el contingut, en la mesura que reconeixem la dialèctica de contraris, el trànsit. La separació implica un deslligament de dues esferes que abans eren» una mateixa, desfer els nusos que uneixen la realitat $i$ allò que no és; en la separació es deslliga el no-ser del ser; quelcom es desperta en la realitat que és, apareix i, poc a poc, es configura com a nova realitat. Oscil-lacions que van determinant la mesura interna del moviment, del temps.

L'espasa és el mitjà per a fer la separació, l'espasa brillant de la saviesa, del discerniment; l'espasa que talla pels dos cantons, retornant cada cosa al seu lloc ${ }^{10}$. L'espasa, l'arma de la mà dreta, s'infereix bruscament sobre una realitat que és, i pel seu rigor, el no-ser que apareix i que es determinarà com a realitat que és, serà en la mesura que el seu «ja-ser» aparegut sigui com el seu primer ser, per tant com «abans-eras; moviment de retorn, o millor, ritme intern del moviment, del sentit universal.

La lluita del guerrer amb el lleó és simbòlicament la teoria del canvi que proposem; està en el llindar d'un traspàs de realitat: continuant essent dintre d'un ser que apareix en la negació del ser que com a realitat és ${ }^{11}$. Podem entendre aquesta lluita com un exemple ${ }^{12}$, els capitells dels claustres romànics i post-romànics, n'hi ha molts per Catalunya; per diferents coincidències formals

"Igual com fa X. Zubiri, Naturaleza, Historia, Dios, Madrid 1978, pp. 71 -72.

10 Sobre I'espasa ofr. M. DURAND, Las estructuras antropológicas de lo imaginario. Madrid 1982, p. 155.

11 Com arriba P. DiEl en el seu procés de lectura psicològica: cfr. El simbolismo en la mitologia griega, Barcelona 1976, Pp. 177-205.

12 I seguint les propostes de M. SCHNEIDER. El origen musical de los animales símbolos, Barcelona 1964, i de R. BERTHELOR. La pensée de l'Asie et l'astrobiologie, Paris 1949. 
ens interessa el de S? Ma de l'Estany. En aquest claustre la forma quadrada es relaciona amb les quatre direccions, de manera que hi ha el nord, el sud, l'est i l'oest. D'aquestes direccions el nord i el sud estan clarament diferenciats, mentre que una descriu tota la vida de Crist, l'altra està constituïda sols per capitells ornamentals; l'una és el dia, l'altra la nit, el moviment segueix el sentit universal. La unió del nord i el sud ve donada respectivament per l'est i l'oest, per on surt el sol i per on es pon; l'alba i el crepuscle, els moments dels trànsits, dels canvis de realitat, en aquestes zones hi ha dos capitells que mostren cadascun una lluita entre un guerrer i un lleó, al costat corresponent al naixement del día, el guerrer s'imposa al lleó, al costat del crepuscle a l'inrevés, relació dialèctica entre els principis discernits; dinàmica del moviment.

Diu l'Evangeli de St. Tomàs: ajesús ha dit, Benaventurat el lleó menjat per l'home, ja que el lleó es tornarà home, i maleït l'home menjat pel lleó, ja que l'home es tornarà lleós. Això és dintre del nostre discurs, en la lluita les dues forces contraposades són simbòlicament el lloc on es produeix una crisi, que comportarà un canvi d'esferes de realitat. En el claustre de Sa Ma de l'Estany en el mateix capitell que hi ha la lluita que anuncia l'alba, hi ha, com en el Castell d'Urgellet, una escena cortesana, una escena que seguint els esquemes i el funcionament formal i de contingut anterior ens mostra una nova esfera de realitat històrica.

Les relacions dintre l'imaginari sobre els exemples de lluites són inacabables: l'Arcàngel Miquel, Sigfrit, Sant Jordi, Shiva, Heràclit, etc. ${ }^{13}$. Les dotze feines d'Heràclit es disposen com en un claustre, de manera que determinen un quadrat; l'inici i la fi es troben, es corresponen, lògicament, amb els dotze signes del zodíac, que ací podem dir les dotze atèmpores» del moviment universal, o els dotze tons de la divisió harmònica; els diferents matisos de les friccions del moviment per la direcció del sentit universal; l'univers té so. El personatge que s'enfronta inevitablement a aquesta roda ha de superar les distintes proves, les reaccions al sentit que cerca ser-complert; les lluites són les crisis al traspàs de dues esferes de realitat.

L'animal és, en principi, l'entitat que es contraposa al personatge $i$ al seu sentit, perquè al personatge li és alhora intern i extern; li és intern en la mesura que té un moviment que és animat.

13 Cfr. M. DURANT, op. cit., pp. 149 iss. 
que respira i, per tant, condensa en el seu cos un microcosmos que recull una realitat ampla i diversa; $i$ li és extern al personatge en la mesura que l'animal és la forma pròpia lligada a la terra, que solidifica en un microcosmos l'esperit baix, inferior, fosc. El moviment cíclic existeix fonamentalment en un transcórrer entre la llum i la fosca, o entre dalt i baix; l'un necessita a l'altre com un pas necessita a l'anterior. La teoria del personatge que proposem el determina com el que pot fer el moviment complert per les atèmpores» de l'univers; com el viatge en tant que parteix i arriba.

El personatge és simbòlicament el temps com a sentit rítmic i macrocòsmic; és el temps perquè és allò que a l'hora (en-eltemps) és el sol i és la lluna; és allò que lliga el dia a la nit i la nit al dia. Li és escaient al personatge ser-moviment, i per això, el nostre tema o motiu és tant proper a la pintura com a la música: al personatge se l'entén dançant, coordinant harmònicament els gestos; en les estructures constructives del final del segle XII l'ordenament de la realitat es centra en el moviment ondulant d'una entitat -tant l'entitat pròpia del cant, com de la pintura, com dels gestos rituals. La pintura (vinculada al sistema constructiu que estilisticament diem Romànic) està dançant, coordinant en l'entitat que-és-el-seu-cos els ritmes ondulants, el sentit i les resistències del macrocosmos. Els personatges d'aquesta dança representen un moviment cíclic, de trànsit de realitats; el personatge és el sentit que lluita contra-els-contra/sentits, que transita entre esferes de realitat ${ }^{14}$. Les dances representen el dramatisme inevitable de les friccions del ritme universal, són l'ordenament del temps en tant que no és etern, que viu, però que no era i que serà mort.

Ês important d'assenyalar que en parlar del motiu iconogràfic d'una lluita entre un guerrer i un lleó parlem estríctament del conflicte entre dues esferes de realitat, en cap moment del desenllaç. La lluita no és ací entesa com el medi per la victòria, sinó com un so determinat, un esglaó imprescindible per tal que l'escala sigui escala.

La lluita està en el límit d'una realitat, hi ha un tomb del procés d'una realitat i per això, és profundament, la unió; la lluita contra la bèstia és la lluita contra el guardià, aquell que està a la porta i que és la porta; la lluita és una unió que introdueix, que és aen el començaments, que estríctament inicia.

14 Cfr. G. Dumézil. Mito y epopeya, Barcelona 1977. pp. 203 i ss.. pel sentit escatològic de la dança. 
La lluita, i bàsicament la lluita d'un home contra una bèstia o un drac, assumeix la morfologia d'aprehensió del símbol del trànsit, és inici, entrada. El possible triomf en aquesta lluita és la superació de la resistència a l'entrada, la resistència dialèctica al ser-moviment; en la lluita hi ha la decisió, darrera d'ella alló inevitable; la lluita és començament i separació, i per tant, moviment.

En la lluita hi ha la proposta d'un canvi complet, a partir d'ella - com inici-s'entra en una altra esfera de propietat, en un altre regne que es defineix en relació a ser-el-contrari, com a diferència completa, a tots els nivells: a qualsevol realitat d'aquest regne (allò-que-és) li correspon en l'altre regne (allò-que-no-és) un contrari particular. El contrari -el-contra/sentit- és una esfera de realitat delimitable, perquè és la realitat que no-és-la-que-és. La que és i la que no-és es complementen, i l'una necessita a l'altra com el dia necessita la nit.

Quan davant d'una obra d'art com el fris del Castell d'Urgellet podem desprendre'ns dels postulats de la història de l'art, descobrim en ell un aspecte, absolutament important, de cognisció; el veurem llargament. En les obres d'art situades en els limits històrics, en els canvis, com en la del Castell d'Urgellet, es descobreix - es revela - particularment el caire cognoscent. El canvi del segle XII és especialment important dintre de la història perquè la variació és bàsicament en la qüestió que volem indicar; això és, el canvi entre les obres que diem romàniques i les posteriors està en que les darreres deixaran de ser obres-cognoscents ${ }^{15}$.

Aproximant la reflexió del ser-cognoscent-de-l'obra en l'escena de la lluita que ens interessa, arribaríem a situar la nostra ment - a l'espectador - en *coincidència» amb el ritme ondulant que proposa l'estructura de l'obra. El ritme construït i constructor de la plàstica s'entrecreua amb la latència de la reflexió; les formes plàstiques i les operacions mentals segueixen, en el seu discórrer. un mateix impuls. L' «artefaciós plàstica en el Castell d'Urgellet és la demostració-d'una-coincidència: el saber-se l'objecte en el subjecte. Ací l'operació plàstica s'ordena i opera simbòlicament.

is Cfr. per a aquesta relació la inflexió que fa J. E. RUIz DOMENEC. „El laberin. to cortesano de la caballerías, Medievalia, monografia-2, 1982, pp. 138 iss. 
En el dramatisme de la lluita hi ha la seva pròpia font-decontinguts; en la representació visualitzada d'una lluita entre un guerrer i un animal s'espera el canvi, no sols es sol-licita com a problema de lectura.

Simbolisme de canvi, simbolisme fonamental de la divisió de contraris; separació primera - primordial- que dóna peu al Temps; aixồ és: al moviment entre allò-no-creat (etern) i allòcreat (no-etern); el Temps es defineix en tant que creació, que dualitat. Allò no creat es diferencia d'allò creat perquè aquest darrer és etern (no-temps). El Temps a la inversa és el no-de-l'eternitat, l'esfera contrària que conté totes i cadascuna de les realitats de l'eternitat. La saviesa que li correspon a l'home que crea artefactes - pensaria l'autor del fris del Castell d'Urgellet - està en la demostració del ritme que es mou entre un ser (forma) i el seu no-ser, entre el so i el silenci. El cos d'aquesta demostració és l'obra, el fris.

La història de l'art no veu l'aspecte cognoscent que tenen internament les pintures del Castell d'Urgellet, per ella li és necessària l'estètica; però les obres d'art que estan prop del Romànic, com a sistema de construcció, estan apartades de l'estètica; són obres que s'immiscueixen, primerament $i$ en sentit ampli, en un camp simbòlic, i com a desglossament d'aquesta pertanyença apareix un segon nivell d'immisció: el ser-cognoscent, la contenció com impuls de la latència rítmica del sentit de l'Univers; això és: la Unitat primera, el repòs on va tot moviment.

L'encadenament que produeix el ritme de l'obra és clarament de caràcter ternari: el retorn a $A$ després d'estar en $B(=$ no-A). En la tercera tèmpora el moviment és realment complert. En la lluita del guerrer amb espasa i cuirassa amb el lleó està clar que hi ha la dualitat, la presentació de dues esferes de realitat; es tracta d'una unió que presenta el conflicte entre aquesta-realitat i la que no-ésaquesta. La lluita és, en el sentit ampli, un interval, una creació de so - fricció - una dualitat. Podem dir, doncs, que és el número 2 .

Però el número 2 inclou el número 3 d'aquesta manera: el 2 és allò segon que és una dualitat, i, per tant, tenim primer l'u (el 
no-segon) i a més els dos propis del segon; és l'esquema gràfic dels nombres constituit un triangle, els nombres secrets ${ }^{1 /}$.

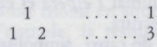

I també en el moviment el número 3 implica el $4^{17}$. En efecte, quan en una operació rítmica - de moviment - s'encadena el número 2 i el 3, (això és unió de separaciô) existeix, inevitablement, un altre pas, el desencadenament de totes les realitats. El número 2 i el 3 s'encadenen com també, abans, l'u s'encadena amb el 2 , però a partir del 3 es des-encadena el número 4, que són, ja, totes les coses i que sobretot és un retorn a la unitat; el 4 torna a ser com l'u ${ }^{18}$.

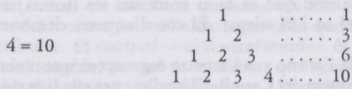

Els nombres ens permeten arribar des de les formes que reconeixem en les icones fins a l'abstracció que ens ha de permetre teoritzar el moviment, situar-se en el nucli d'ell. És difícil operant com la lluita, que no es reconegui en l'escena del Castell d'Urgellet la proposta d'aquesta teoria, és una lluita construïda en la dialèctica del moviment.

En una obra d'art simbòlica sempre s'apunta a un mateix principi de significació, darrera de les formes hi ha l'objectiu que *coincideix» amb l'aprehensió del subjecte; podriem parlar d'estructura temporalitzada, ja que el que importa tant en l'objecte com en el subjecte és la dinamització, l'estar habitant en el Temps. No podem confondre una obra d'art cognoscent amb un problema objectual, sinó que hem de vigilar, atents, l'objectiu, el sentit en definitiva. L'obra d'art simbòlica es defineix, doncs, per l'acció que comporta, pels ritmes que encadenen i desencadenen.

És complex el Temps, ni tan sols sé si m'he aproximat a ell, de tota manera resta el fris.

16 Cfr. G. Jouven. Les nombres cachés, Paris 1978, pp. 91 iss.

17 Cfr. A. REGHINI, Les nombres Sacrés. Milà 1981, pp. 71 i ss.

I8 Com diu el TAO-Te-King: aL'u porta al dos, el dos porta al tres i després totes les cosess. Per la igualtat $4=10$ vegeu les dues notes anteriors. 